\title{
Clinical and CT manifestations of coronavirus disease 2019 (COVID-19): comparison of suspected cases of COVID-19 in isolation and non-COVID-19 pneumonia in a single-center study conducted in Beijing, China
}

Heng Liu

Department of Radiology, PLA Rocket Force Characteristic Medical Center, Beijing

Weihua Li

Department of Radiology, PLA Rocket Force Characteristic Medical Center, Beijing

Lei Zhang

Department of Emergency, PLA Rocket Force Characteristic Medical Center, Beijing

Bing Liu

Department of Disease control and prevention, PLA Rocket Force Characteristic Medical Center, Beijing Chaoying Qi

Department of Radiology, PLA Rocket Force Characteristic Medical Center, Beijing

Wei Fan

Department of Radiology, PLA Rocket Force Characteristic Medical Center, Beijing

Pei Feng

Department of Radiology, PLA Rocket Force Characteristic Medical Center, Beijing Jingjing Pan ( $\sim$ panjingjing3969@sina.com )

Department of Radiology, PLA Rocket Force Characteristic Medical Center, No.16 Xinwai Street, Xicheng District, Beijing 100088, China

Fengyuan Man

Department of Radiology, PLA Rocket Force Characteristic Medical Center, Beijing

\section{Research}

Keywords: corona virus disease 2019, COVID-19; severe acute respiratory syndrome coronavirus 2, SARSCoV-2, pneumonia, Computed tomography, CT

Posted Date: May 11th, 2020

DOI: https://doi.org/10.21203/rs.3.rs-27288/v1 
License: (c) (i) This work is licensed under a Creative Commons Attribution 4.0 International License. Read Full License 


\section{Abstract}

Background: The clinical and CT manifestations of COVID-19 pneumonia and non-COVID-19 pneumonia in the same period have not been compared in detail. The purpose of this study is to analyze the clinical and CT manifestations of COVID-19 pneumonia and perform a comparison of those isolated patients for presumed COVID-19 infection and of non-COVID-19 pneumonia in the same period.

Methods: 173 patients with pneumonia from January 1, 2020 to March 20, 2020 were retrospectively enrolled and classified into three groups: patients with COVID-19 pneumonia (Group I, N=4), patients in hospital-isolation for presumed COVID-19 pneumonia (Group $\mathbb{Q}, \mathrm{N}=5$ ), and patients with non-COVID-19 pneumonia (Group III, N=163). Clinical symptoms, laboratory test results and CT imaging features were compared among three groups.

Results: Fever and cough were the most common clinical symptoms in the three groups. $30 / 163$ (18.4\%) patients were asymptomatic in Group III. Leukopenia, lymphocytopenia, and elevated C-reactive protein was identified in 1 (25\%), 1 (25\%), and 1 (25\%) patient in Group I; 1 (20\%), 1 (20\%), and 2 (40\%) patients in Group II; 10/157 (6.4\%), 33/157(21.0\%), and 94/136 (69.1\%) patients in Group III. Demarcated GGO/mixed GGO, ill-defined GGO/mixed GGO, consolidation, centrilobular nodule, tree-in bud opacity, bilateral involvement, peripheral distribution, posterior part/lower lobe predilection was observed in $3 / 4$ (75\%), 2/4 (50\%), 4/4 (100\%), 2/4 (50\%), 0,3/4 (75\%), 3/4 (75\%), and 2/4 (50\%) patients, respectively in Group I; $1 / 5$ (20\%), 5/5 (100\%), 4/5 (80\%), 4/5 (80\%), 3/5 (60\%), 4/5 (80\%), 2/5 (40\%), and 3/5 (60\%)

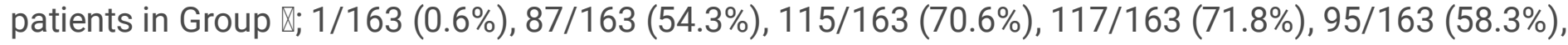
52/163 (31.9\%), 9/163 (5.5\%), and 9/163 (5.5\%) patients in Group III, respectively.

Conclusions: Demarcated GGO and consolidation prefer the diagnosis of COVID-19 pneumonia, whereas ill-defined GGO and consolidation, centrilobular nodule surrounded by GGO, and tree-in-bud opacity are preferred for non-COVID-19 pneumonia. chest CT has potential in early identification of COVID-19 and implementation of isolation for appropriate case.

\section{Introduction}

In December 2019, cases of "unknown origin" pneumonia caused by a novel coronavirus, which was designated coronavirus disease 2019 (COVID-19) by the World Health Organization (WHO), were first reported in Wuhan, China (1-3). COVID-19 was caused by a novel virus, named as severe acute respiratory syndrome coronavirus 2 (SARS-CoV-2). On March 11, 2020, the WHO declared that the outbreak of COVID-19 had been characterized as a global pandemic. As of May 4th, 2020, a total of 3,565,899 infected cases and 248,367 death cases had been reported worldwide.

Owing to the lack of specific therapeutic drugs or vaccines for COVID-19, early diagnosis, isolation, and treatment have been proven to play an extremely important role in controlling the spread of the epidemic. According to the program for the diagnosis and treatment of COVID-19 pneumonia published by the National Health Commission, the diagnosis of COVID-19 must be confirmed by reverse transcription 
polymerase chain reaction (RT-PCR) or gene sequencing for respiratory or blood specimens (4). However, owing to limited capacity for the RT-PCR test, improper sample collection or transportation and inconsistent kit performance, the successful RT-PCR analysis for throat and nasal swab samples was initially limited (5-9). In contrast with RT-PCR, chest CT has a higher sensitivity for COVID-19 detection than RT-PCR test (8-10). The CT imaging characteristics of COVID-19 include GGO, consolidation, crazypaving pattern, interlobular septa thickening with a predilection of peripheral distribution, and a tendency for bilateral involvement (9-12). However, they were not specific or overlapping $(11,13,14)$. Moreover, as the period of the COVID-19 outbreak coincides with the influenza epidemic period, many influenza virus pneumonia and community-acquired pneumonia cases have emerged during the epidemic of COVID-19 pneumonia (13-15). Recently, an increasing number of cases of asymptomatic COVID-19 infection have been reported. Therefore, distinguishing COVID-19 pneumonia from non-COVID-19 pneumonia is of particular importance, which allows for early implementation of isolation, helps avoid unnecessary quarantine, public panic, excessive consumption of medical resources, and reduces the risk of cross infection. To the best of our knowledge, few studies have focused on the differences between COVID-19 and non-COVID-19 pneumonia in the same period. Therefore, this study aimed to analyze the clinical and CT manifestations of COVID-19 pneumonia and perform a comparison of those isolated patients for presumed COVID-19 infection and of non-COVID-19 pneumonia in the same period to help early disease identification and avoid unnecessary patient isolation.

\section{Materials And Methods}

\section{Study design}

This study was approved by the Medical Ethical Management Committee of our institutional review board. As a retrospective study, the requirement for patients' informed consent was waived in accordance with the CIOMS guidelines. A total of 368 consecutive patients diagnosed with the diagnosis of "pneumonia" by chest CT scan in our institutional PACS from January 1 to March 20, 2020 were reviewed. The diagnosis of pneumonia was in accordance with the 2007 guidelines of the Infectious Diseases Society of America and the American Thoracic Society (16), and the exclusion criteria included pneumonia-like CT appearance caused by mosaic perfusion effect or a hypostasis effect, obstructive atelectasis caused by tumor, compressed atelectasis caused by pleural effusion, and other non-infectious or non-inflammatory diseases. Finally, 172 patients were enrolled in this study (Figure 1).

\section{Clinical Data Collection}

The available clinical data, including age, sex, clinical history, laboratory findings, time course of symptoms, and travel and exposure history, were extracted from electronic medical records (Table 1). Laboratory assessments consisted of blood leucocyte count, lymphocyte count, and C-reactive protein, and detection of common respiratory tract infection pathogens, including adenovirus, respiratory syncytial virus (RSV), influenza virus, legionella pneumophila, human parainfluenza virus (HPIV), 
Mycoplasma pneumoniae, and Chlamydia pneumoniae; other pathogenic agents were also recorded if detected.

\section{Chest CT and Imaging Interpretation}

All patients underwent chest CT examination in a supine position during end-inspiration without intravenous contrast material and a $2.5 \mathrm{~mm}$-thick slice was imaged using a BrightSpeed scanner (GE Medical Systems, Milwaukee, WI, USA). Two thoracic radiologists (with more than 5 and 8 years of experience) blinded to the clinical data reviewed the CT images independently; in cases of disagreement, consensus was achieved by consulting with a third radiologist with 18 years of experience. All images were reviewed on both lung (width, $1500 \mathrm{HU}$; level, $-400 \mathrm{HU}$ ) and mediastinal (width, $400 \mathrm{HU}$; level, $40 \mathrm{HU}$ ) settings.

The following CT features were recorded: ground-glass opacity (GGO)/mixed GGO, consolidation, interlobular septa thickening, crazy-paving pattern, centrilobular nodular, reticulation, bronchial wall thickening, tree-in-bud opacity (TIB), traction bronchiectasis, cavitation, calcification, vascular enlargement, pleural effusion, and lymphadenopathy (defined as lymph node size of $\geq 10 \mathrm{~mm}$ in the short-axis dimension). The detailed descriptions of the features mentioned above were provided by the Fleischner Society (17). GGO/mixed GGO was subdivided as demarcated or ill-defined based on the boundary. In accordance with preliminary studies $(5,18)$, we introduced a scoring system to semiquantitatively assess the severity of COVID-19 based on the degree of involvement of the five lung lobes: score 0 , no involvement of a lung lobe; score $1,1 \%-25 \%$ involvement; score $2,26 \%-50 \%$ involvement; score $3,51 \%-75 \%$ involvement; and score $4,76 \%-100 \%$ involvement. The overall severity score of the five lung lobes ranged from to $0-20$. The distribution of lesions was recorded as peripheral distribution, posterior part or lower lobe predilection, and bilateral involvement. For those patients who received followup chest $\mathrm{CT}$, we also analyzed all the $\mathrm{CT}$ films of each examination.

\section{Results}

\section{Patient demographics}

Based on the clinical symptoms, laboratory results, and CT imaging findings, we classified a total of 172 patients (95 men and 77 women; age range, 19-98 years of age; mean age, 63.6 years of age) into three

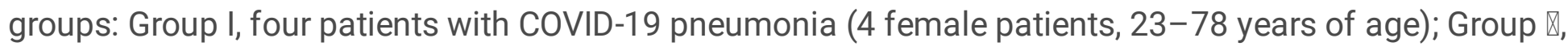
five patients in hospital-isolation for presumed COVID-19 pneumonia (4 male and 1 female patients, 2567 years of age, median age, 38 years of age); and Group III, 163 patients with non-COVID-19 pneumonia (91 male and 72 female patients, 19-98 years of age, mean age, 64.1 years of age). All the five patients in Group II were isolated in our institutional fever observation department for presumed infection of COVID-19 pneumonia. With the exception of one patient who was transferred to a designated institution for COVID-19 for a definite exposure history (husband of a confirmed case of COVID-19 in Group I) who was eventually determined not to be infected, the other four patients were relieved from quarantine later 
with a series of negative results of RT-PCR test and improvement of lesions on follow-up CT scans. The patients' clinical data and laboratory test results are summarized in Table 1.

\section{Table 1. Patients' clinical symptoms and laboratory results}




\begin{tabular}{|c|c|c|c|}
\hline & Group $\square(\mathrm{N}=4)$ & Group $\square(\mathrm{N}=5)$ & Group $\square(N=163)$ \\
\hline \multicolumn{4}{|l|}{ Sex } \\
\hline Men & 0 & 4 & 91 \\
\hline Women & 4 & 2 & 72 \\
\hline Age $(y)^{\&}$ & $63(22)$ & $38(26)$ & $64 \pm 20$ \\
\hline \multicolumn{4}{|l|}{ Exposure history } \\
\hline Definite exposure & 0 & $2(40 \%)$ & $\mathrm{N} / \mathrm{A}$ \\
\hline Unknown exposure & 4 & $3(60 \%)$ & $\mathrm{N} / \mathrm{A}$ \\
\hline \multicolumn{4}{|l|}{ Clinical symptoms } \\
\hline Fever & $4(100 \%)$ & $5(100 \%)$ & $73(44.8 \%)$ \\
\hline Cough & $1(25 \%)$ & $2(40 \%)$ & $65(39.9 \%)$ \\
\hline Expectoration & $1(25 \%)$ & $2(40 \%)$ & $60(36.8 \%)$ \\
\hline Pharyngalgia & 0 & 0 & $31(19.0 \%)$ \\
\hline Fatigue & $1(25 \%)$ & $2(40 \%)$ & $4(2.5 \%)$ \\
\hline Headache & $1(25 \%)$ & $1(20 \%)$ & $6(3.7 \%)$ \\
\hline Myalgia & 0 & 0 & $4(2.5 \%)$ \\
\hline Nausea & 0 & 0 & $6(3.7 \%)$ \\
\hline Vomiting & 0 & 0 & $6(3.7 \%)$ \\
\hline Diarrhea & 0 & $1(20 \%)$ & $1(0.6 \%)$ \\
\hline No obvious symptoms & 0 & 0 & $30(18.4 \%)$ \\
\hline \multicolumn{4}{|l|}{ RT-PCR test } \\
\hline Positive & 4 & 0 & $\mathrm{~N} / \mathrm{A}$ \\
\hline Negative & 0 & 5 & $\mathrm{~N} / \mathrm{A}$ \\
\hline \multicolumn{4}{|l|}{ Laboratory test* } \\
\hline \multicolumn{4}{|l|}{ Blood leucocyte count } \\
\hline Normal & $1(25 \%)$ & $2(40 \%)$ & $87 / 157(55.4 \%)$ \\
\hline Increased $\left(>9.16 * 10^{\wedge} 9 / \mathrm{L}\right)$ & $2(50 \%)$ & $2(40 \%)$ & $60 / 157(38.2 \%)$ \\
\hline Decreased $\left(<3.69 * 10^{\wedge} 9 / \mathrm{L}\right)$ & $1(25 \%)$ & $1(20 \%)$ & $10 / 157(6.4 \%)$ \\
\hline Lymphocyte count & & & \\
\hline
\end{tabular}




\begin{tabular}{|llll|}
\hline Normal & $3(75 \%)$ & $4(80 \%)$ & $122 / 157(77.7 \%)$ \\
\hline Increased $\left(>4 * 10^{\wedge} 9 / \mathrm{L}\right)$ & 0 & 0 & $2 / 157(1.3 \%)$ \\
\hline Decreased $\left(<0.8 * 10^{\wedge} 9 / \mathrm{L}\right)$ & $1(25 \%)$ & $1(20 \%)$ & $33 / 157(21.0 \%)$ \\
\hline C-reactive protein & & & \\
\hline Normal & $1(25 \%)$ & $3(60 \%)$ & $42 / 136(30.9 \%)$ \\
\hline Increased $(>10 \mathrm{mg} / \mathrm{L})$ & $3(75 \%)$ & $2(40 \%)$ & $94 / 136(69.1 \%)$ \\
\hline Influenza ${ }^{* \#}$ & $\mathrm{~N} / \mathrm{A}$ & $1(1)$ & $\mathrm{N} / \mathrm{A}$ \\
\hline Mycoplasma $^{* \#}$ & $1(1)$ & $0(2)$ & 4 \\
\hline Fungus $^{* \#}$ & $\mathrm{~N} / \mathrm{A}$ & $\mathrm{N} / \mathrm{A}$ & 17 \\
\hline Other pathogens & $\mathrm{N} / \mathrm{A}$ & $\mathrm{N} / \mathrm{A}$ & 24 \\
\hline
\end{tabular}

Note- RT-PCR: reverse transcription polymerase chain reaction;

\&: median age $(\mathrm{IQR})$ for Group $\otimes(\mathrm{N}=4)$ and Group $\otimes$, mean age $\pm \mathrm{SD}$ for Group $\otimes$

N/A: No investigation or test performed; ${ }^{*}$ : Not all patients received the test

\#: The number in parentheses represented total number of patients received test

\section{Exposure history}

One patient in Group II had a history of traveling to Wuhan 16 days before the onset of fever. The other patients in Group II and all four patients in Group I had unknown exposure history. As this was a retrospective study, the investigation of exposure history was not performed for patients in Group III.

\section{Signs and symptoms}

The most common clinical manifestations of patients in Group I were fever (100\%), cough (25\%), expectoration ( $25 \%)$, headache (25\%), and fatigue (25\%). The same results were found in Group II; in addition, diarrhea was observed in one patient. The symptoms at onset of illness in Group III were fever (44.8\% of 41 patients), cough (39.9\%), expectoration (36.8\%), pharyngalgia (19.0\%), vomiting (7.4\%), headache $(3.7 \%)$, fatigue $(2.5 \%)$, myalgia (2.5\%), and diarrhea $(0.6 \%) ; 18.4 \%$ of patients were asymptomatic.

\section{Laboratory tests}


Normal leucocytes, leukocytosis, leukopenia, lymphocytopenia, and elevated C-reactive protein was identified in 1 (25\%), 2 (50\%), 1 (25\%), 1 (25\%), and 3 (75\%) patients in Group I, and 2 (40\%), 2 (40\%), 1 (20\%), 1 (20\%), and $2(40 \%)$ patients in Group II, respectively. Elevated C-reactive protein was observed in $68.9 \%$ of patients in Group III and leukopenia was less common (6.4\%) in Group III. In addition, one patient was positive for mycoplasma in Group I and one patient had a weakly positive result for influenza B virus in Group II. In Group III, two patients were positive for Mycoplasma pneumoniae, 17 patients were positive for fungi, and 24 were positive for other pathogens, including gram-positive bacteria, gramnegative bacteria, Pseudomonas aeruginosa, Klebsiella pneumoniae, and Staphylococcus epidermis.

\section{CT imaging findings}

The CT features of all patients enrolled in this study are listed in Table 2.

\section{Table 2. Chest CT features of $\mathbf{1 7 2}$ patients in three groups}




\begin{tabular}{|c|c|c|c|}
\hline & Group I (N=4) & Group II $(\mathrm{N}=5)$ & Group III $(\mathrm{N}=163)$ \\
\hline \multicolumn{4}{|l|}{ Distribution } \\
\hline Peripheral distribution & $3(75 \%)$ & $2(40 \%)$ & $9(5.5 \%)$ \\
\hline Posterior part/lower lobe predilection & $2(50 \%)$ & $3(60 \%)$ & $9(5.5 \%)$ \\
\hline Bilateral involvement & $3(75 \%)$ & $4(80 \%)$ & $52(31.9 \%)$ \\
\hline Involved lung lobe ${ }^{*}$ & 4 (range, 1-5) & 4 (range, 2-5) & 2 (range, 1-5) \\
\hline Lung involvement score ${ }^{*}$ & 4 (range, 1-19) & 4 (range, 2-8) & 2.8 (range, 1-14) \\
\hline GGO/mixed GGO & $4(100 \%)$ & $5(100 \%)$ & $88(54.0 \%)$ \\
\hline demarcated & $3(75 \%)$ & $1(20 \%)$ & $1(0.6 \%)$ \\
\hline Ill-defined & $2(50 \%)$ & $5(100 \%)$ & $87(53.4 \%)$ \\
\hline Consolidation & $4(100 \%)$ & $4(80 \%)$ & $115(70.6 \%)$ \\
\hline Air bronchogram & $4(100 \%)$ & $3(60 \%)$ & $75(46.0 \%)$ \\
\hline Halo & $1(25 \%)$ & $2(40 \%)$ & $15(9.2 \%)$ \\
\hline Bronchial wall thickening & $2(50 \%)$ & $2(40 \%)$ & $76(46.6 \%)$ \\
\hline Traction bronchiectasis & 0 & 0 & $12(7.4 \%)$ \\
\hline Reverse-halo & $1(25 \%)$ & 0 & $1(0.6 \%)$ \\
\hline Vascular enlargement & $2(50 \%)$ & 0 & $10(6.1 \%)$ \\
\hline Interlobular septal thickening & $2(50 \%)$ & $2(40 \%)$ & $34(20.9 \%)$ \\
\hline Crazy-paving pattern & $1(25 \%)$ & $2(40 \%)$ & $7(4.3 \%)$ \\
\hline Reticulation & 0 & 0 & $8(4.9 \%)$ \\
\hline Cetrilobular nodule & $2(50 \%)$ & $4(80 \%)$ & $117(71.8 \%)$ \\
\hline Tree-in-bud opacity & 0 & $3(60 \%)$ & $95(58.3 \%)$ \\
\hline Cavitation & 0 & 0 & $7(4.3 \%)$ \\
\hline Calcification & 0 & 0 & $5(3.1 \%)$ \\
\hline Pleural thickening & 0 & 0 & $22(13.5 \%)$ \\
\hline Pleural effusion & $1(25 \%)$ & 0 & $24(14.7 \%)$ \\
\hline Hydropericardium & 0 & 0 & $3(1.8 \%)$ \\
\hline Lymphadenopathy & 0 & 0 & $1(0.6 \%)$ \\
\hline
\end{tabular}


Note *: The number in Group $\nabla$ and $\otimes$ was median and mean in Group $\nabla$. GGO: ground-glass opacity

Group I: Three (75\%) patients had a peripheral distribution of multiple demarcated GGO/mixed GGO and consolidation involving bilateral lungs, consistent with typical CT features of viral pneumonia (Figure 1). The median of involved lung lobes and lung involvement score was 4 (range, 1-5) and 4 (range, 1-19). An air bronchogram was observed in 4 (100\%) patients, bronchial/bronchiolar wall thickening in 2 (50\%) patients (Figure 2), interlobular septal thickening in 2 (50\%) patients (Figure 3), crazy-paving pattern in 1 (25\%) patient, and reverse-halo sign in 1 (25\%) patient (Figure 2). Bilateral pleural effusion was observed in one patient diagnosed with severe COVID-19 pneumonia with ARDS (Figure 3). In addition, ill-defined GGOs and centrilobular nodules were found in two patients with leukocytosis (Figure 2, 3). No patient showed tree-in-bud signs. Pure consolidation with incomplete halo was observed in only one patient who was initially diagnosed with Mycoplasma pneumoniae (Figure 4). Owing to recurrent fever during hospitalization, a second CT scan 9 days later showed obvious progression with an increased lung involvement score from 1 to 5 , and the diagnosis of COVID-19 infection was made due to the positive RTPCR results for the third time (Figure 4).

Group II: All 5 (100\%) patients presented bilateral involvement with a median lung involvement score of 4 (range, 2-8) and 3 (75\%) presented a posterior part or lower lobe predilection. GGO was present in all patients (100\%), but demarcated GGO/mixed GGO was present in only 1 (20\%) patient (Figure 5). Peripheral distribution of lesions as well as interlobular septa thickening and crazy-paving pattern were observed in 2 (40\%) patients (Figure 5 and 6). Centrilobular nodules, TIB, consolidation, and halo were observed in 4 (80\%), 3 (75\%), 3 (80\%), and 2 (40\%) patients (Figure $7-9)$.

Group III: Consolidation was observed in 117 (71.8\%) patients in Group III. Of these 117 patients, air bronchogram, bronchial wall thickening, incomplete halo, and complete halo was were in $46.0 \%, 46.6 \%$, $1.8 \%$, and $7.4 \%$ of patients, respectively. Centrilobular nodules (71.8\%) and TIB (58.3\%) were more common than those in Group I. III-defined GGO was observed in 53.4\% of patients and demarcated GGO, which was more common (75\%) in Group I, was observed in only one patient (0.6\%). Only 5.5\% and 31.9\% of patients showed peripheral distribution and bilateral involvement, respectively. The mean lung involvement score was 2.8, and the highest involvement score was 14, and the minimum was 1 (Figure 10). Moreover, interlobular septa thickening, crazy-paving pattern, reticulum, pleural thickening, and pleural effusion were observed in $20.9 \%, 4.3 \%, 4.9 \%, 13.5 \%$, and $14.7 \%$ of patients, respectively.

\section{Discussion}

The purpose of this study was to identify patients with COVID-19 from those patients who presented with pneumonia in CT imaging and to isolate suspected patients as early as possible and avoid unnecessary isolation. In this retrospective study, the most common clinical symptoms of Group I (COVID-19 pneumonia) were fever and cough, same to Group II (presumed COVID-19 pneumonia) and III (non-COVID- 
19 pneumonia). 30 (18.4\%) patients in Group III were asymptomatic. Myalgia (4, 2.5\%), nausea (6, 3.7\%), vomiting $(6,3.7 \%)$, and diarrhea $(1,0.6 \%)$ were only observed in Group III and only one patient presented with diarrhea in Group II.

Normal or slightly decreased white blood cell count and decreased lymphocyte count are the main laboratory manifestations of early stage of $\operatorname{COVID-19}(1,7,19,20)$. The incidence of lymphopenia, normal or decreased WBC count, and elevation of C-reactive protein in this study was $25 \%(1 / 4), 50 \%(2 / 4)$, and $75 \%(3 / 4)$, respectively. Three (75\%) patients in Group I were initially excluded from the suspicion of COVID-19 as leukocytosis was observed in two and positive mycoplasma result observed in one.

Typical CT imaging features of COVID-19 pneumonia have been widely reported $(11,12,21-23)$, however, they are not specific and may be present in pneumonia caused by various pathogens $(13,14)$. . Bilateral multifocal GGOs with peripheral distribution, most common CT manifestation of COVID-19(13, 14), was observed in three (75\%) patients , five (100\%) and 88 (54.0\%) in Group I, II and III, respectively.

Interestingly, demarcated GGO was only preset in one patient in Group II $(1,20 \%)$ and III $(1,0.6 \%)$, whereas present in three (75\%) patients in Group I. To the best of our knowledge, few studies have focused on the margin of GGO in COVID-19, so we reviewed previous literatures and found that majority of GGOs were demarcated $(1,5-12,19-28)$. The pathological process during the early stage of COVID-19, including dilatation and congestion of alveolar septal capillary, exudation of fluid in alveolar cavity and interlobular interstitial edema, was considered to cause single or multiple scattered patchy or agglomerated GGOs, separated by grid-like thickened interlobular septa (20).

Consolidation was considered as progression of GGO in $\operatorname{COVID-19}(20,29)$. Pure consolidation, focal lesions and lesions involving single lung lobe were less common in COVID-19 (20). Only one patient in Group I showed purely ill-defined consolidation with an incomplete halo at the onset of illness, the other consolidations present in Group I were well-defined without halo. Halo was observed in two (40\%) patients in Group II and 15 (9.2\%) patients in Group III.

Centrilobular nodules and TIB are generally considered to reflect a bronchogenic dissemination and are common in bronchiolitis caused by mycobacteria, bacteria, viruses, other organisms, and aspiration (3033). Single or multiple solid nodules or centrilobular nodules surrounded by GGO are atypical CT imaging manifestations of COVID-19 pneumonia (20). Multiple solid nodules or centrilobular nodules surrounded by GGO were observed in $2(50 \%)$ patients with leukocytosis in Group I, $4(80 \%)$ patients in Group II and $117(71.8 \%)$ patients in Group III. TIB was observed in three (60\%) patients in Group II and 95 (58.3\%) patients in Group III, but was not observed in Group I. As evidence of probable mixed infection has been reported (34) we supposed the centrilobular nodules in Group I might be caused by co-infection.

Bilateral lung involvement, peripheral distribution, and posterior part or lower lung lobe predilection were reported as typical distribution of COVID-19 $(11,12,21,24)$. Bilateral multiple GGOs and patchy consolidations were observed in three patients in Group I, one patient in Group II, and 52 (31.9\%) patients in Group III showed bilateral lung involvement. Only 9 (5.5\%) patients showed peripheral distribution and posterior or lower lobe predilection. 
Our study has some limitations. Firstly, there were only four cases of COVID-19 pneumonia. As Beijing is not an epidemic area of COVID-19 and our institution is not a designated hospital for COVID-19, there are relatively few cases of COVID-19. Secondly, there may have been some selection bias. Exposure history and RT-PCR test were not available in Group III, and the diagnosis of non-COVID-19 pneumonia was made by clinical symptoms, elevated inflammatory biomarkers, and abnormal opacities on CT imaging (16). As a result, some patients may have been incorrectly classified. Thirdly, follow-up CT scans were not available for all patients.

\section{Conclusions}

In summary, bilateral involvement of multifocal demarcated GGO and well-defined consolidation with a peripheral distribution were typical CT manifestations of COVID-19 pneumonia. III-defined GGO consolidation with halo, centrilobular nodule surrounded by GGO, and tree-in-bud opacity without a peripheral distribution or bilateral involvement are preferred for non-COVID-19 pneumonia. These research findings of our study suggest that chest CT has potential in early identification of COVID-19 and implementation of isolation for appropriate case.

\section{Abbreviations}

COVID-19: corona virus disease 2019

RT-PCR: reverse transcription polymerase chain reaction

GGO: ground-glass opacity

TIB: tree-in-bud opacity

\section{Declarations}

\section{Ethics approval and consent to participate}

This study was approved by the Medical Ethical Management Committee of our institutional review board. As a retrospective study, the requirement for patients' informed consent was waived in accordance with the CIOMS guidelines.

\section{Consent for publication}

Not applicable.

\section{Availability of data and materials}

The datasets during and/or analyzed during the current study are available from the corresponding author on reasonable request. 


\section{Competing interests}

The authors declare that they have no competing interests.

\section{Funding:}

This work was supported by the National Natural Science Foundation of China (NSFC) (Grant No. 81901872).

\section{Author contributions}

Guarantors of integrity of entire study, H.L., W.H., L.Z., B.L., J.P., F.M.; study design, all authors; data acquisition and interpretation, all authors; manuscript drafting and revision, H.L., W.H., L.Z., B.L., J.P.; approval of final version of submitted manuscript, all authors; agrees to ensure any questions related to the work are appropriately resolved, all authors; literature research, H.L., W.H., C.Q., W.F., P.F., J.P.; clinical studies, H.L., W.H., L.Z., B.L., J.P.; statistical analysis, H.L., W.H., C.Q., W.F., P.F., J.P.; and manuscript editing, H.L., W.H., J.P., F.M.

Corresponding Author: Jingjing Pan, MD

Department of Radiology, PLA Rocket Force Characteristic Medical Center, No.16 Xinwai Street, Xicheng District, Beijing, 100088, China. E-mail: panjingjing3969@sina.com

\section{Acknowledgments:}

The authors would like to express their appreciation for all the emergency services, nurses, doctors, and other hospital staff for their efforts in controlling the spread of the COVID-19 epidemic.

\section{References}

1. Huang C, Wang Y, Li X, Ren L, Zhao J, Hu Y, Zhang L, Fan G, Xu J, Gu X, Cheng Z, Yu T, Xia J, Wei Y, Wu W, Xie X, Yin W, Li H, Liu M, Xiao Y, Gao H, Guo L, Xie J, Wang G, Jiang R, Gao Z, Jin Q, Wang J, Cao B. Clinical features of patients infected with 2019 novel coronavirus in Wuhan, China. Lancet 2020;395(10223):497-506. doi: 10.1016/S0140-6736(20)30183-5

2. Phelan AL, Katz R, Gostin LO. The Novel Coronavirus Originating in Wuhan, China: Challenges for Global Health Governance. JAMA 2020. doi: 10.1001/jama.2020.1097

3. Lu R, Zhao X, Li J, Niu P, Yang B, Wu H, Wang W, Song H, Huang B, Zhu N, Bi Y, Ma X, Zhan F, Wang L, Hu T, Zhou H, Hu Z, Zhou W, Zhao L, Chen J, Meng Y, Wang J, Lin Y, Yuan J, Xie Z, Ma J, Liu WJ, Wang D, Xu W, Holmes EC, Gao GF, Wu G, Chen W, Shi W, Tan W. Genomic characterisation and epidemiology of 2019 novel coronavirus: implications for virus origins and receptor binding. Lancet 2020;395(10224):565-574. doi: 10.1016/S0140-6736(20)30251-8

4. Committee GOoNH, Medicine OoSAoTC. Notice on the issuance of a program for the diagnosis and treatment of novel coronavirus (2019-nCoV) infected pneumonia (trial sixth edition) (2020-02-19). 
2020.

5. Xie X, Zhong Z, Zhao W, Zheng C, Wang F, Liu J. Chest CT for Typical 2019-nCoV Pneumonia: Relationship to Negative RT-PCR Testing. Radiology 2020:200343. doi: 10.1148/radiol.2020200343

6. Wang D, Hu B, Hu C, Zhu F, Liu X, Zhang J, Wang B, Xiang H, Cheng Z, Xiong Y, Zhao Y, Li Y, Wang X, Peng Z. Clinical Characteristics of 138 Hospitalized Patients With 2019 Novel Coronavirus-Infected Pneumonia in Wuhan, China. JAMA 2020. doi: 10.1001/jama.2020.1585

7. Guan WJ, Ni ZY, Hu Y, Liang WH, Ou CQ, He JX, Liu L, Shan H, Lei CL, Hui DSC, Du B, Li LJ, Zeng G, Yuen KY, Chen RC, Tang CL, Wang T, Chen PY, Xiang J, Li SY, Wang JL, Liang ZJ, Peng YX, Wei L, Liu Y, Hu YH, Peng P, Wang JM, Liu JY, Chen Z, Li G, Zheng ZJ, Qiu SQ, Luo J, Ye CJ, Zhu SY, Zhong NS, China Medical Treatment Expert Group for C. Clinical Characteristics of Coronavirus Disease 2019 in China. N Engl J Med 2020. doi: 10.1056/NEJMoa2002032

8. Ai T, Yang Z, Hou H, Zhan C, Chen C, Lv W, Tao Q, Sun Z, Xia L. Correlation of Chest CT and RT-PCR Testing in Coronavirus Disease 2019 (COVID-19) in China: A Report of 1014 Cases. Radiology 2020:200642. doi: 10.1148/radiol.2020200642

9. Fang Y, Zhang H, Xie J, Lin M, Ying L, Pang P, Ji W. Sensitivity of Chest CT for COVID-19: Comparison to RT-PCR. Radiology 2020:200432. doi: 10.1148/radiol.2020200432

10. Huang P, Liu T, Huang L, Liu H, Lei M, Xu W, Hu X, Chen J, Liu B. Use of Chest CT in Combination with Negative RT-PCR Assay for the 2019 Novel Coronavirus but High Clinical Suspicion. Radiology 2020;295(1):22-23. doi: 10.1148/radiol.2020200330

11. Song F, Shi N, Shan F, Zhang Z, Shen J, Lu H, Ling Y, Jiang Y, Shi Y. Emerging 2019 Novel Coronavirus (2019-nCoV) Pneumonia. Radiology 2020;295(1):210-217. doi: 10.1148/radiol.2020200274

12. Chung M, Bernheim A, Mei X, Zhang N, Huang M, Zeng X, Cui J, Xu W, Yang Y, Fayad ZA, Jacobi A, Li K, Li S, Shan H. CT Imaging Features of 2019 Novel Coronavirus (2019-nCoV). Radiology 2020;295(1):202-207. doi: 10.1148/radiol.2020200230

13. Koo HJ, Lim S, Choe J, Choi SH, Sung H, Do KH. Radiographic and CT Features of Viral Pneumonia. Radiographics 2018;38(3):719-739. doi: 10.1148/rg.2018170048

14. Franquet T. Imaging of pulmonary viral pneumonia. Radiology 2011;260(1):18-39. doi: 10.1148/radiol.11092149

15. Franquet T. Imaging of Community-acquired Pneumonia. J Thorac Imaging 2018;33(5):282-294. doi: 10.1097/rti.0000000000000347

16. Mandell LA, Wunderink RG, Anzueto A, Bartlett JG, Campbell GD, Dean NC, Dowell SF, File TM, Jr., Musher DM, Niederman MS, Torres A, Whitney CG, Infectious Diseases Society of A, American Thoracic S. Infectious Diseases Society of America/American Thoracic Society consensus guidelines on the management of community-acquired pneumonia in adults. Clin Infect Dis 2007;44 Suppl 2:S27-72. doi: 10.1086/511159

17. Hansell DM, Bankier AA, MacMahon H, McLoud TC, Muller NL, Remy J. Fleischner Society: glossary of terms for thoracic imaging. Radiology 2008;246(3):697-722. doi: 10.1148/radiol.2462070712 
18. Chung M, Bernheim A, Mei X, Zhang N, Huang M, Zeng X, Cui J, Xu W, Yang Y, Fayad ZA, Jacobi A, Li K, Li S, Shan H. CT Imaging Features of 2019 Novel Coronavirus (2019-nCoV). Radiology 2020:200230. doi: 10.1148/radiol.2020200230

19. Zhang JJ, Dong X, Cao YY, Yuan YD, Yang YB, Yan YQ, Akdis CA, Gao YD. Clinical characteristics of 140 patients infected with SARS-CoV-2 in Wuhan, China. Allergy 2020. doi: 10.1111/all.14238

20. Jin YH, Cai L, Cheng ZS, Cheng H, Deng T, Fan YP, Fang C, Huang D, Huang LQ, Huang Q, Han Y, Hu B, Hu F, Li BH, Li YR, Liang K, Lin LK, Luo LS, Ma J, Ma LL, Peng ZY, Pan YB, Pan ZY, Ren XQ, Sun HM, Wang $Y$, Wang YY, Weng H, Wei CJ, Wu DF, Xia J, Xiong Y, Xu HB, Yao XM, Yuan YF, Ye TS, Zhang XC, Zhang YW, Zhang YG, Zhang HM, Zhao Y, Zhao MJ, Zi H, Zeng XT, Wang YY, Wang XH, Management ftZHoWUNC, Research Team E-BMCoCIE, Promotive Association for M, Health C. A rapid advice guideline for the diagnosis and treatment of 2019 novel coronavirus (2019-nCoV) infected pneumonia (standard version). Mil Med Res 2020;7(1):4. doi: 10.1186/s40779-020-0233-6

21. Bernheim A, Mei X, Huang M, Yang Y, Fayad ZA, Zhang N, Diao K, Lin B, Zhu X, Li K, Li S, Shan H, Jacobi A, Chung M. Chest CT Findings in Coronavirus Disease-19 (COVID-19): Relationship to Duration of Infection. Radiology 2020:200463. doi: 10.1148/radiol.2020200463

22. Zu ZY, Jiang MD, Xu PP, Chen W, Ni QQ, Lu GM, Zhang LJ. Coronavirus Disease 2019 (COVID-19): A Perspective from China. Radiology 2020:200490. doi: 10.1148/radiol.2020200490

23. Lei J, Li J, Li X, Qi X. CT Imaging of the 2019 Novel Coronavirus (2019-nCoV) Pneumonia. Radiology 2020;295(1):18. doi: 10.1148/radiol.2020200236

24. Kanne JP. Chest CT Findings in 2019 Novel Coronavirus (2019-nCoV) Infections from Wuhan, China: Key Points for the Radiologist. Radiology 2020;295(1):16-17. doi: 10.1148/radiol.2020200241

25. Hu X, Chen J, Jiang X, Tao S, Zhen Z, Zhou C, Wang J. CT imaging of two cases of one family cluster 2019 novel coronavirus (2019-nCoV) pneumonia: inconsistency between clinical symptoms amelioration and imaging sign progression. Quant Imaging Med Surg 2020;10(2):508-510. doi: 10.21037/qims.2020.02.10

26. Xu X, Yu C, Qu J, Zhang L, Jiang S, Huang D, Chen B, Zhang Z, Guan W, Ling Z, Jiang R, Hu T, Ding Y, Lin L, Gan Q, Luo L, Tang X, Liu J. Imaging and clinical features of patients with 2019 novel coronavirus SARS-CoV-2. Eur J Nucl Med Mol Imaging 2020;47(5):1275-1280. doi: 10.1007/s00259020-04735-9

27. Cao Y, Liu X, Xiong L, Cai K. Imaging and Clinical Features of Patients With 2019 Novel Coronavirus SARS-CoV-2: A systematic review and meta-analysis. J Med Virol 2020. doi: 10.1002/jmv.25822

28. Chen N, Zhou M, Dong X, Qu J, Gong F, Han Y, Qiu Y, Wang J, Liu Y, Wei Y, Xia J, Yu T, Zhang X, Zhang L. Epidemiological and clinical characteristics of 99 cases of 2019 novel coronavirus pneumonia in Wuhan, China: a descriptive study. Lancet 2020;395(10223):507-513. doi: 10.1016/S01406736(20)30211-7

29. Pan F, Ye T, Sun P, Gui S, Liang B, Li L, Zheng D, Wang J, Hesketh RL, Yang L, Zheng C. Time Course of Lung Changes On Chest CT During Recovery From 2019 Novel Coronavirus (COVID-19) Pneumonia. Radiology 2020;0(0):200370. doi: 10.1148/radiol.2020200370 
30. Jeong YJ, Lee KS. Pulmonary tuberculosis: up-to-date imaging and management. AJR Am J Roentgenol 2008;191(3):834-844. doi: 10.2214/AJR.07.3896

31. Leung AN. Pulmonary tuberculosis: the essentials. Radiology 1999;210(2):307-322. doi: 10.1148/radiology.210.2.r99ja34307

32. Webb WR. Thin-section CT of the secondary pulmonary lobule: anatomy and the image--the 2004 Fleischner lecture. Radiology 2006;239(2):322-338. doi: 10.1148/radiol.2392041968

33. Winningham PJ, Martinez-Jimenez S, Rosado-de-Christenson ML, Betancourt SL, Restrepo CS, Eraso A. Bronchiolitis: A Practical Approach for the General Radiologist. Radiographics 2017;37(3):777794. doi: $10.1148 / \mathrm{rg} .2017160131$

34. Ruuskanen O, Lahti E, Jennings LC, Murdoch DR. Viral pneumonia. The Lancet 2011;377(9773):12641275. doi: 10.1016/S0140-6736(10)61459-6

\section{Figures}

368 patients with the diagnosis of "pneumonia" by chest $\mathrm{CT}$ in our institutional PACS from January 1 to March 20, 2020

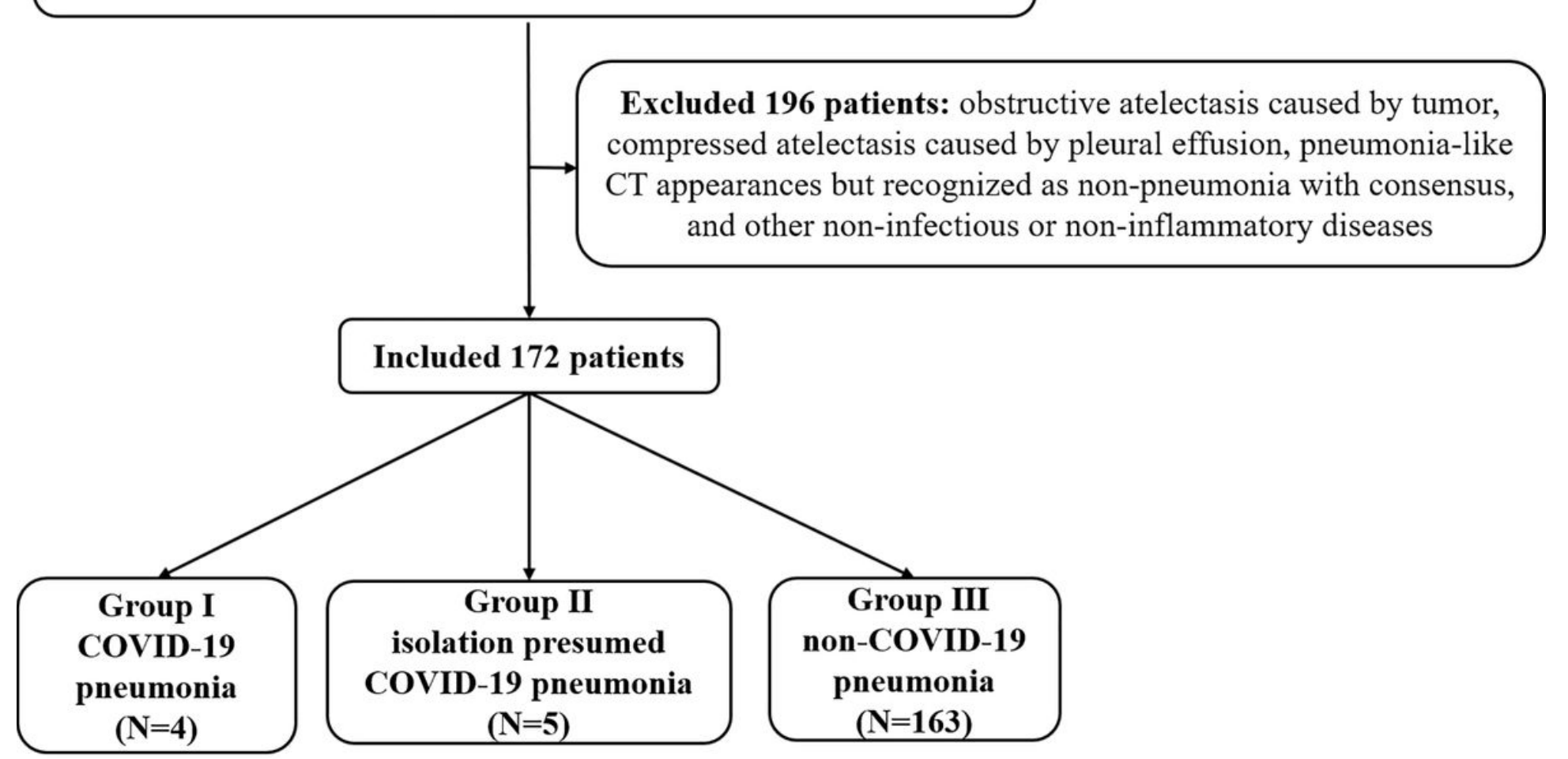

Figure 1

Flowchart of this study. 

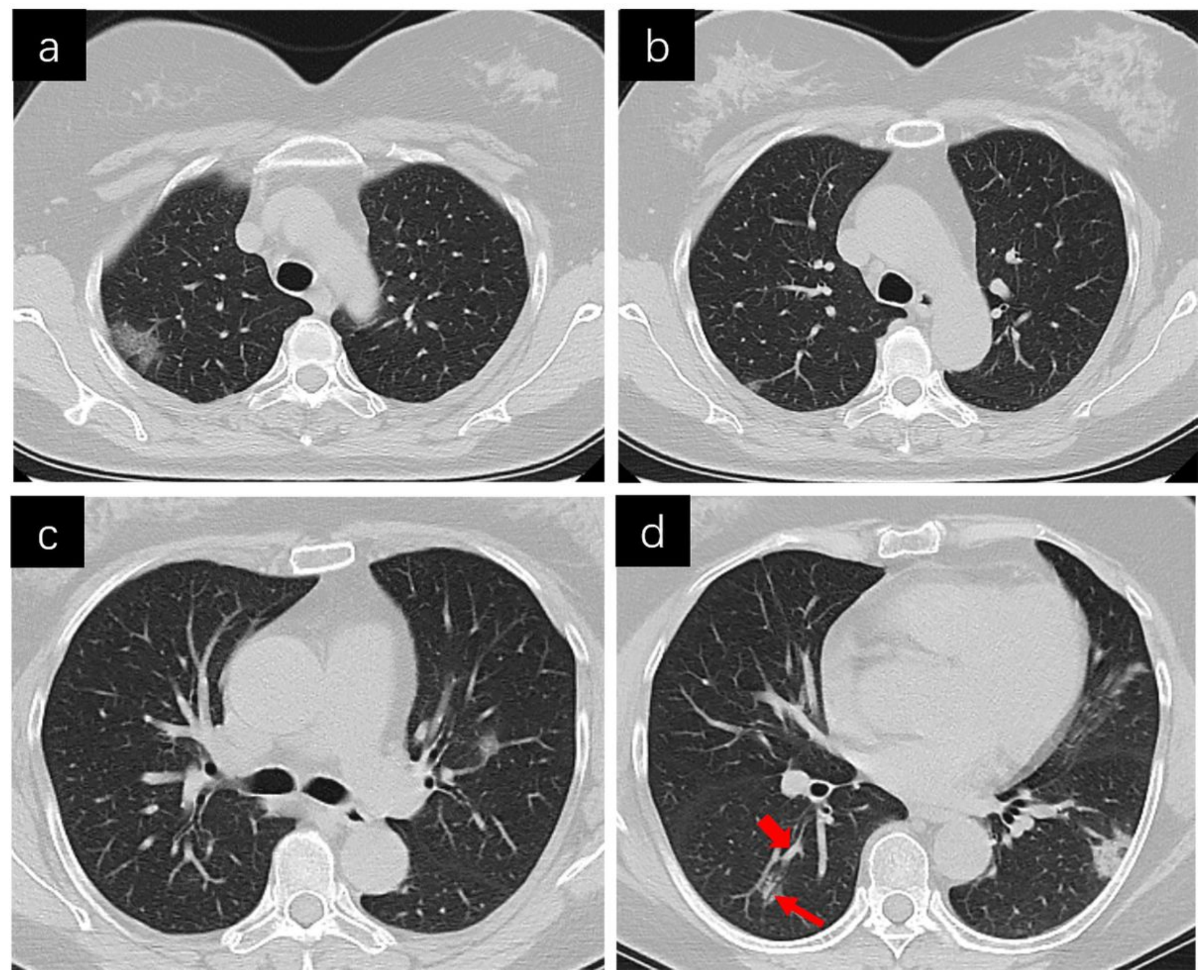

\section{Figure 2}

A 57-year-old woman appeared with fever of $38.5^{\circ} \mathrm{C}$. Laboratory test shows elevated C-reactive protein $(11.91 \mathrm{mg} / \mathrm{L})$ and leukocytopenia $\left(3.49 * 10^{\wedge} 9 / \mathrm{L}\right)$. a-d: Axial unenhanced CT images show multifocal demarcated ground-glass opacities and well-defined consolidations mainly located in the subpleural regions. Crazy-paving pattern (a), air bronchogram (thin arrow) and vascular enlargement (thick arrow) are also present $(\mathrm{d})$. 

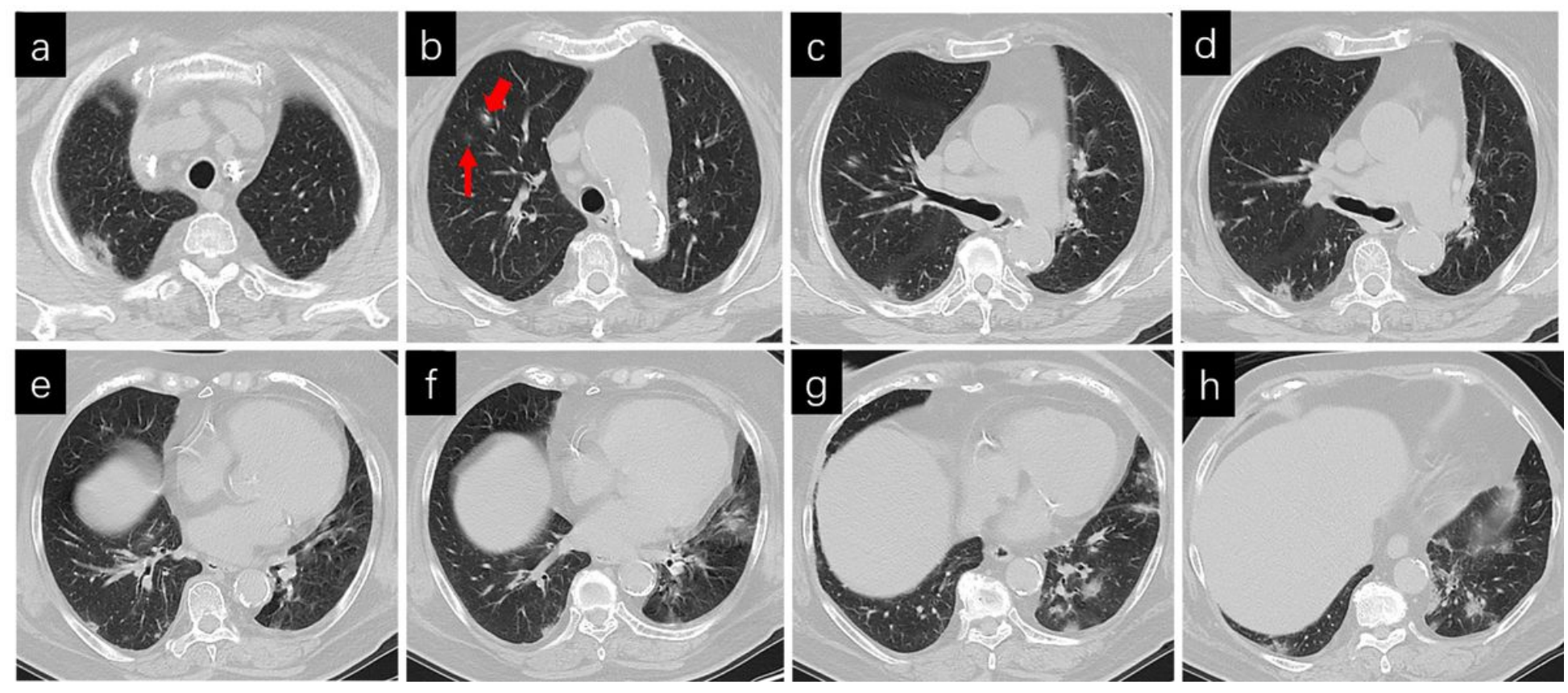

Figure 3

A 78-year-old woman appeared with fever of $37.3^{\circ} \mathrm{C}$, cough and expectoration. Laboratory test shows elevated C-reactive protein $(99.58 \mathrm{mg} / \mathrm{L})$ and leukocytosis $\left(10.37 * 10^{\wedge} 9 / \mathrm{L}\right)$. a-h, Axial unenhanced CT images show bilateral involvement of multifocal demarcated ground-glass opacities and well-defined consolidations with a peripheral distribution. Reverse-halo located in the subpleural region of apical segment of right upper lobe (a) and dorsal segment of right lowed lobe (d), ill-defined ground-glass opacity ( $b$, thin arrow), centrilobular consolidated nodules surrounded by ground-glass opacity ( $b$, thick arrow), discrete nodules (e), and consolidation with halo (f) are also presented. 

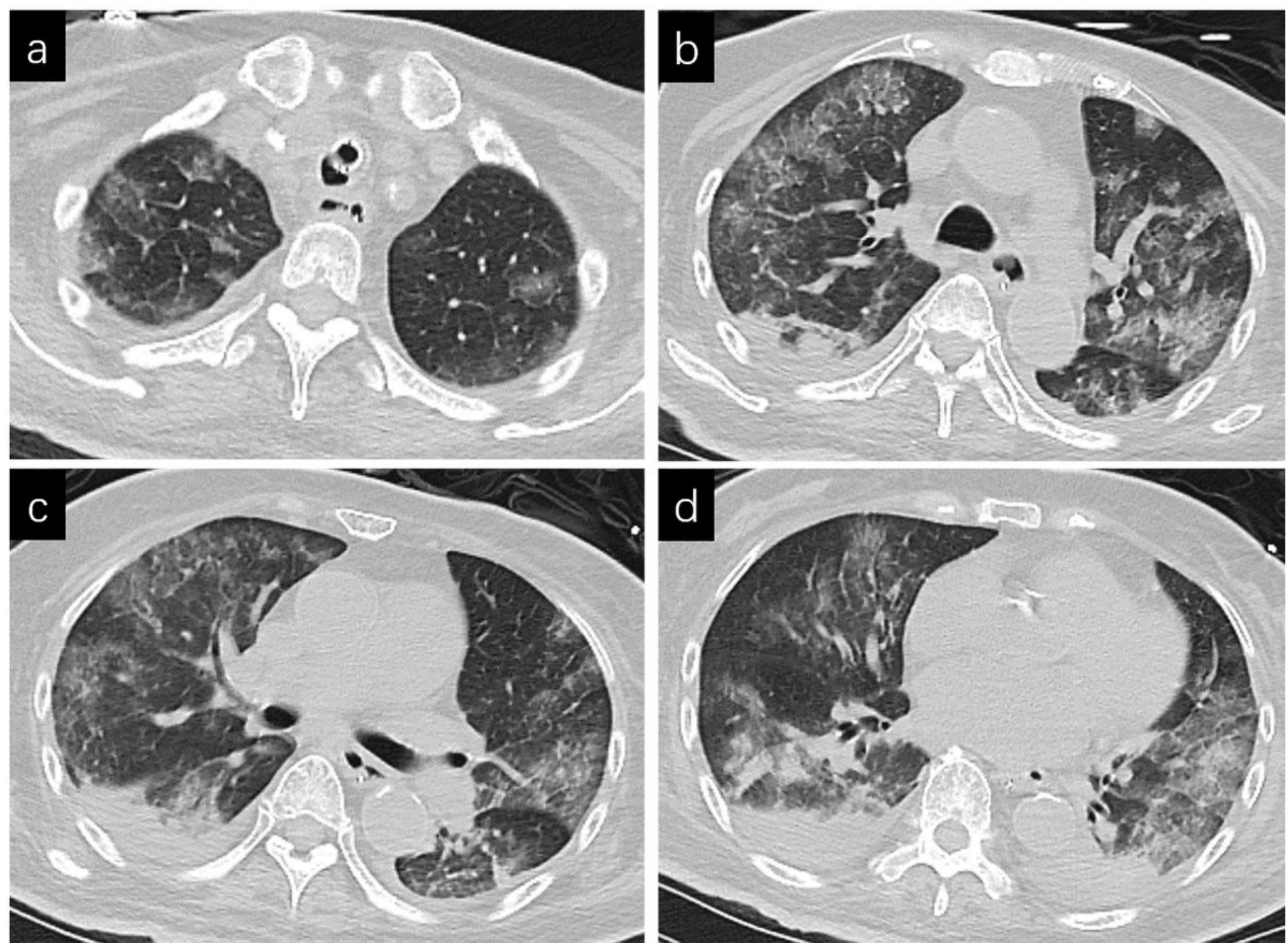

Figure 4

A 68-year-old woman presented fever of $37.7^{\circ} \mathrm{C}$ was admitted to our hospital at the onset of illness. Laboratory test shows elevated C-reactive protein $(200 \mathrm{mg} / \mathrm{L})$, leukocytosis $\left(22.19 * 10^{\wedge} 9 / \mathrm{L}\right)$ and lymphopenia $\left(0.74 * 10^{\wedge} 9 / \mathrm{L}\right)$. a-d: Axial unenhanced CT images show bilateral involvement of demarcated ground-glass opacities/mixed ground-glass opacities and patchy consolidations with a peripheral of subpleural distribution. Interlobular septa thickening $(a, b)$, ill-defined centrilobular nodules surrounded by ground-glass opacity (c), and bilateral pleural effusion (d) are also notable. 

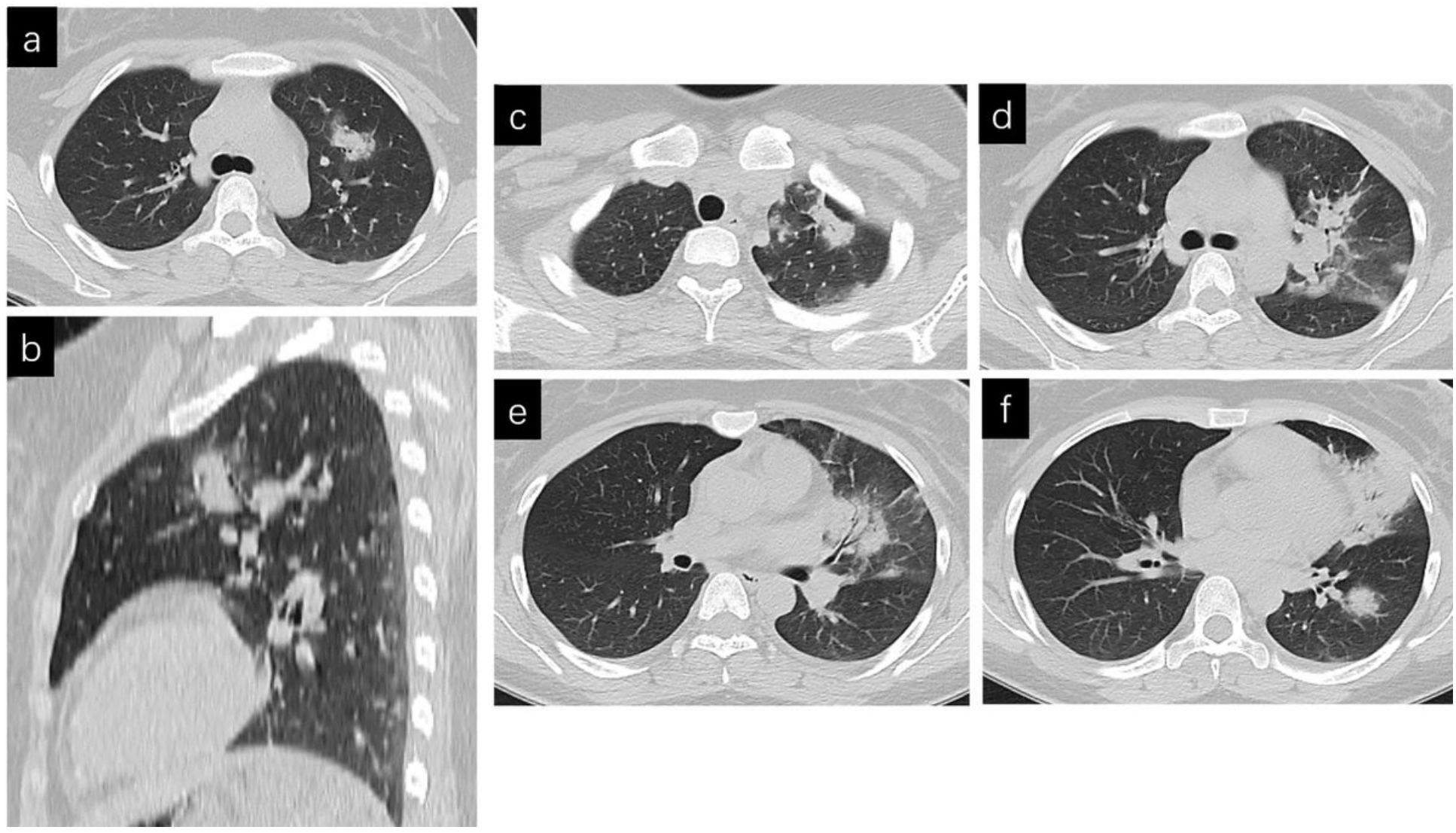

Figure 5

A 23-year-old woman appeared with fever of $38.5^{\circ} \mathrm{C}$, fatigue and headache. Laboratory test proves positive for mycoplasma pneumoniae. Axial unenhanced CT (a) and reconstructed sagittal imaging (b) at the onset of illness show a discriminated consolidation with an incomplete halo in the posterior apical segment of left upper lobe. c-f: The follow-up CT scan 9 days later shows significant progression with new occurrence of multifocal well-defined consolidations with air bronchogram, patchy ground-glass opacities, interlobular septa thickening (c) and fiber cord (d, e). The following third time RT-PCR test confirms COVID-19 infection. 

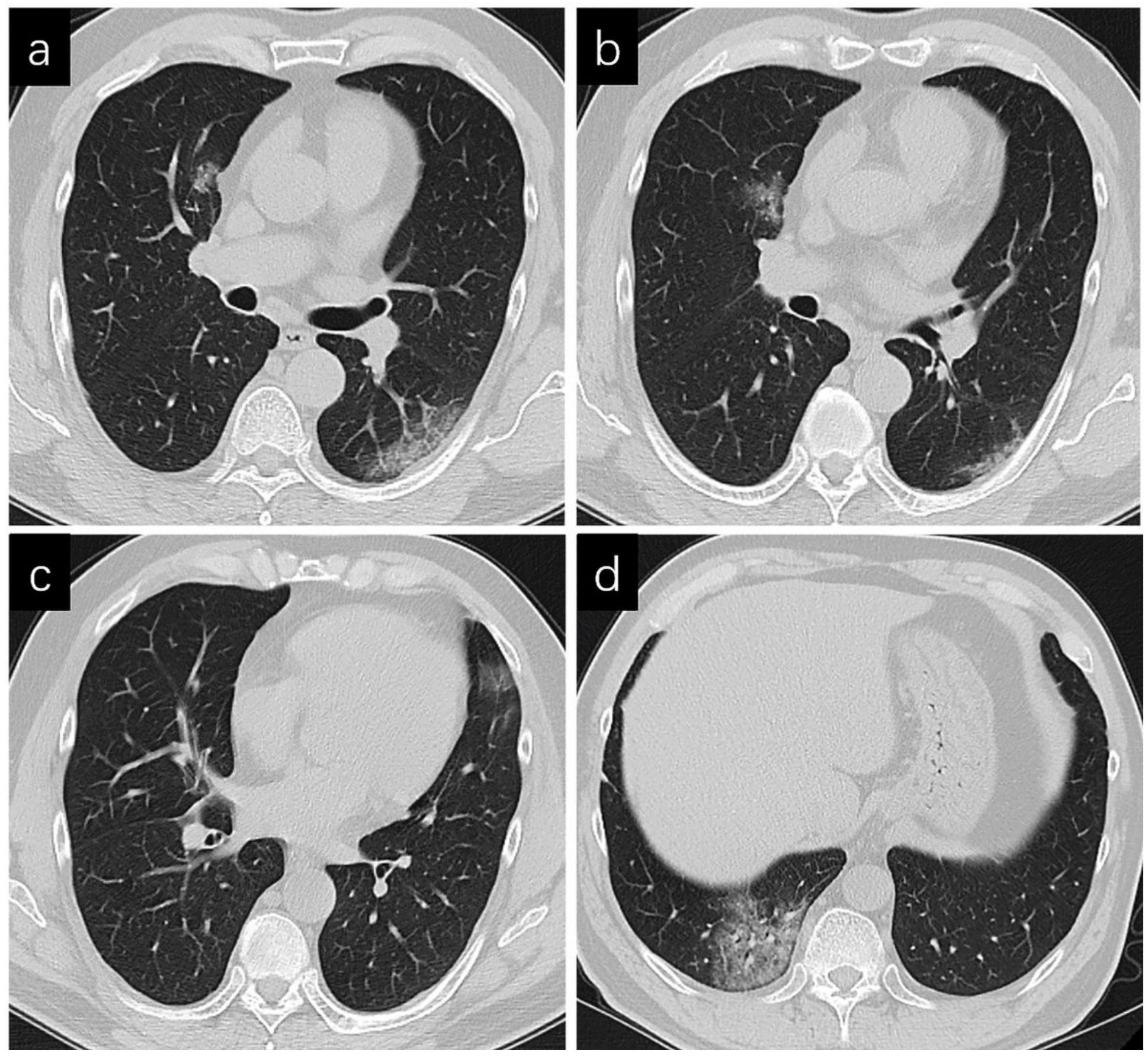

Figure 6

A 60-year-old man, the husband of one COVID-19 infected patient (Figure 2), presented with fever of $37.8^{\circ} \mathrm{C}$, fatigue, headache and diarrhea at the onset of illness. Laboratory test proves leukocytopenia $\left(3.41 * 10^{\wedge} 9 / \mathrm{L}\right)$. a-d: Axial unenhanced CT when he was admitted to our hospital shows multiple demarcated ground-glass opacities and mixed ground-glass opacities, air bronchogram, and crazy-paving pattern (a) mainly located in the peripheral regions of bilateral lower lobes. In spite of the four times negative result of RT-PCR test, he was diagnosed as a suspected case of COVID-19 for a close contact history and was transferred to the designated hospital after five days of isolation and the suspicion of infection was finally excluded by the hospital. 


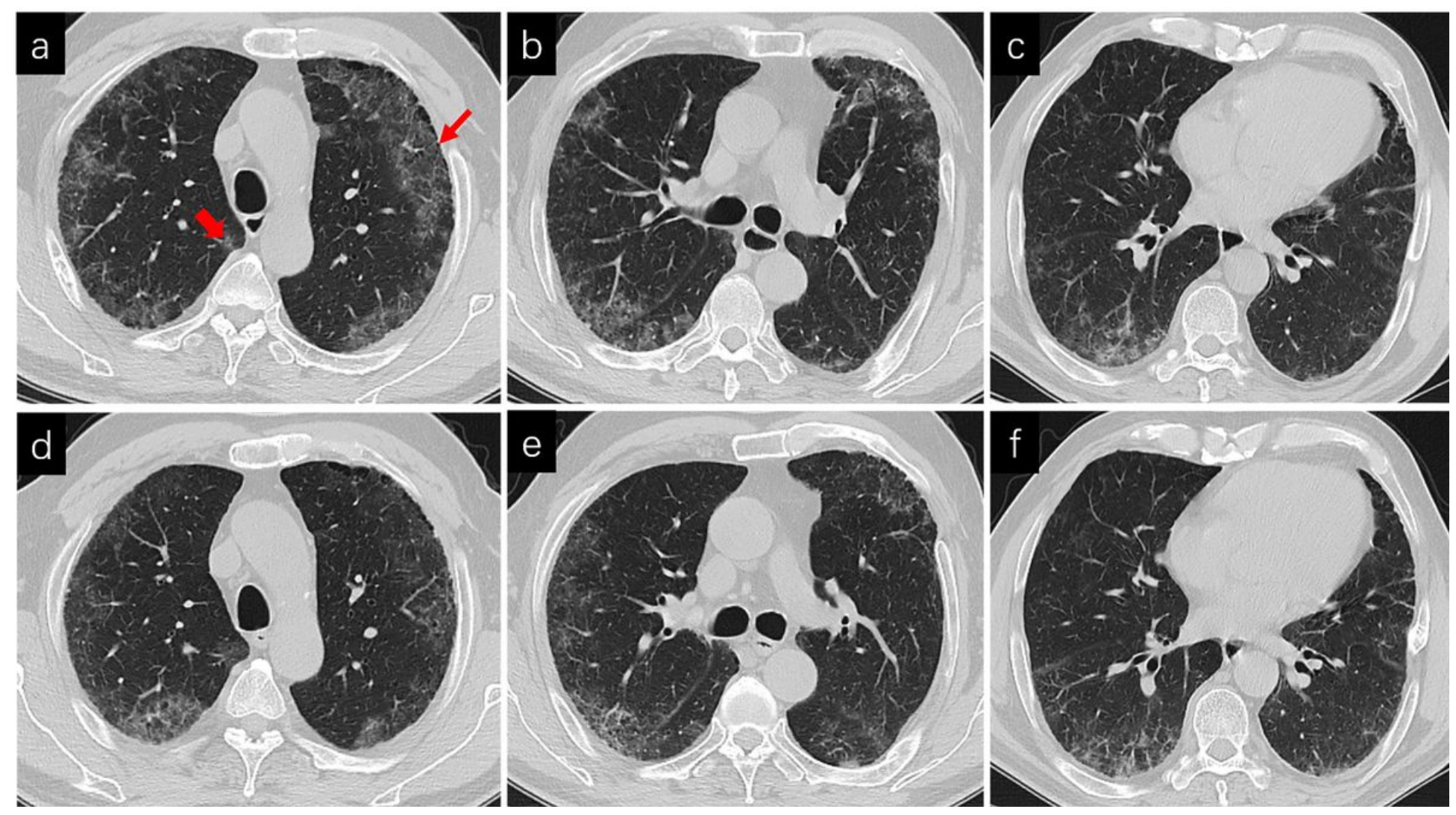

Figure 7

A 67-year-old man presented with dizziness and fever when he was admitted to our hospital. Laboratory test proves elevated C-reactive protein ( $57 \mathrm{mg} / \mathrm{L})$ and leukocytosis $\left(10.63 * 10^{\wedge} 9 / \mathrm{L}\right)$. a-C: Axial unenhanced CT shows a peripheral distribution of crazy-paving pattern (a, thin arrow), ill-defined groundglass opacities (a, thick arrow), tree-in-bud opacity (b) and ill-defined consolidation (c) with bilateral involvement. d-f: The follow-up CT scan 7 days later shows improvement of lesions and the comorbidity of interstitial fibrosis involved bilateral subpleural regions. 

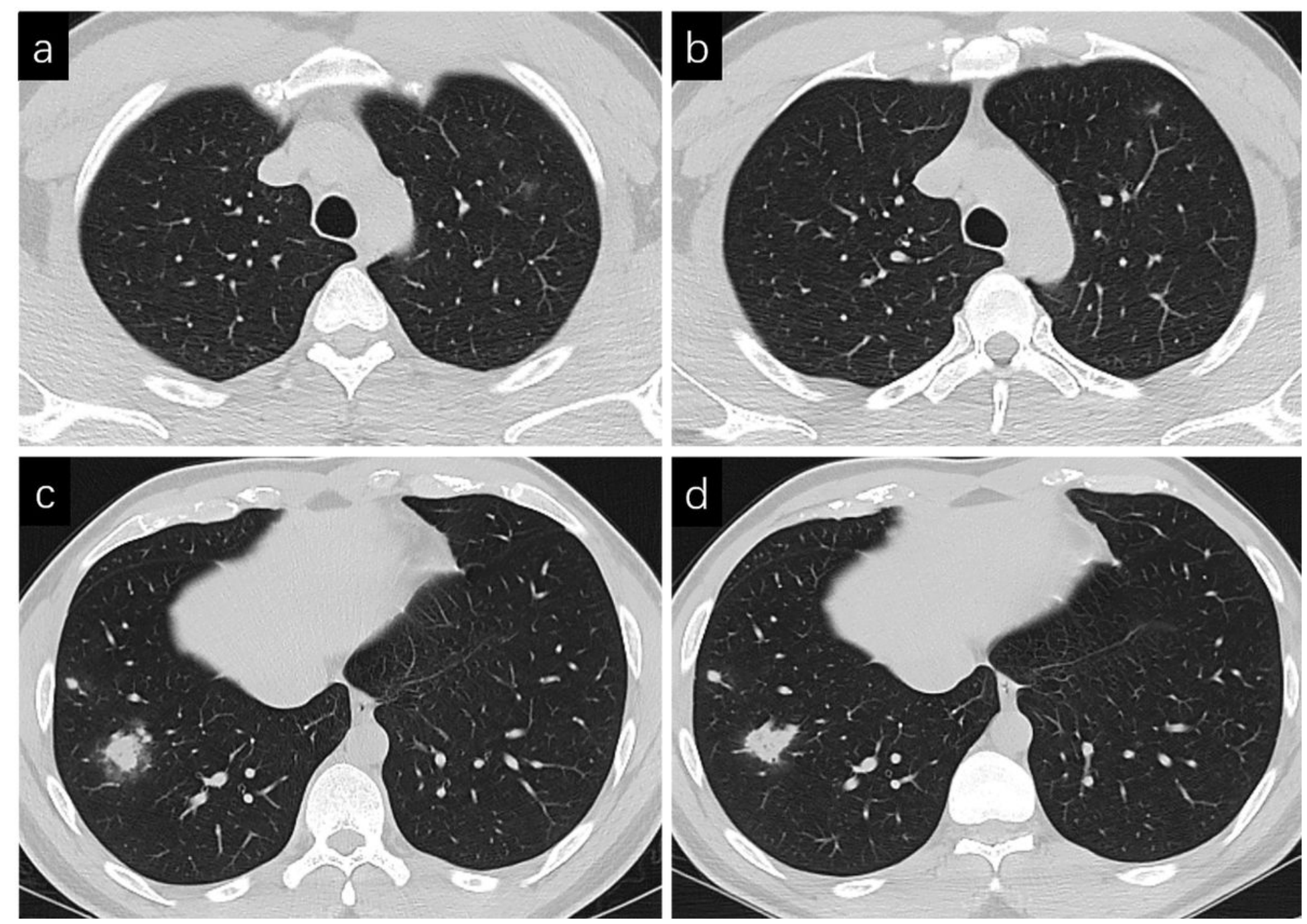

Figure 8

A 25-year-old man who had a history of travelling to Wuhan 16 days before the onset of fatigue and fever of $37.8^{\circ} \mathrm{C}$. Laboratory test proves leukocytosis $\left(11.01 * 10^{\wedge} \mathrm{g} / \mathrm{L}\right)$ and lymphopenia $\left(0.31 * 10^{\wedge} 9 / \mathrm{L}\right)$. a-C: Axial unenhanced CT at the onset of illness shows ill-defined ground-glass opacity (a), centrilobular nodule (b, $c$ ) and a consolidation with a complete halo (c) involved bilateral lung lobes without a peripheral distribution. The follow-up CT scan 24 days later shows partial improvement of previous consolidation in right lower lobe (d). Finally, with four times of negative results for RT-PCR and a weakly positive result for influenza B virus, suspicion of COVID-19 infection was excluded and the patient was released from isolation. 

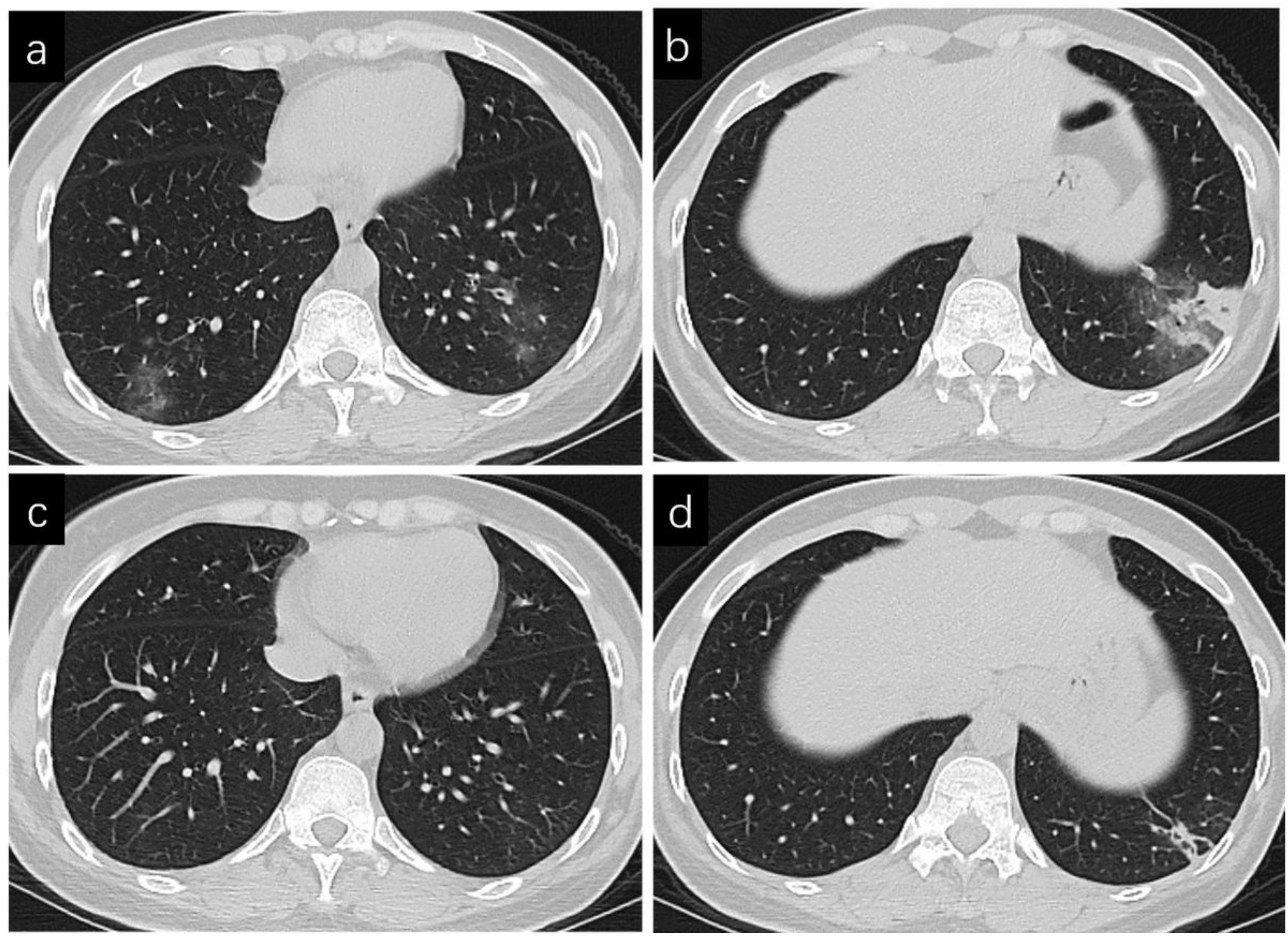

Figure 9

A 38-year-old woman presented with fever of $38^{\circ} \mathrm{C}$ and elevated C-creative protein (54.66 mg/L). The initial axial unenhanced CT three days after the onset of illness shows multiple ill-defined ground-glass opacities (a) involved bilateral lower lung lobes and a consolidation with incomplete halo and air bronchogram in the left lower lung lobe (b). The follow-up CT scan seven days later shows distinguished improvement with only some fibro cord in the left lower lung lobe (c-d). 

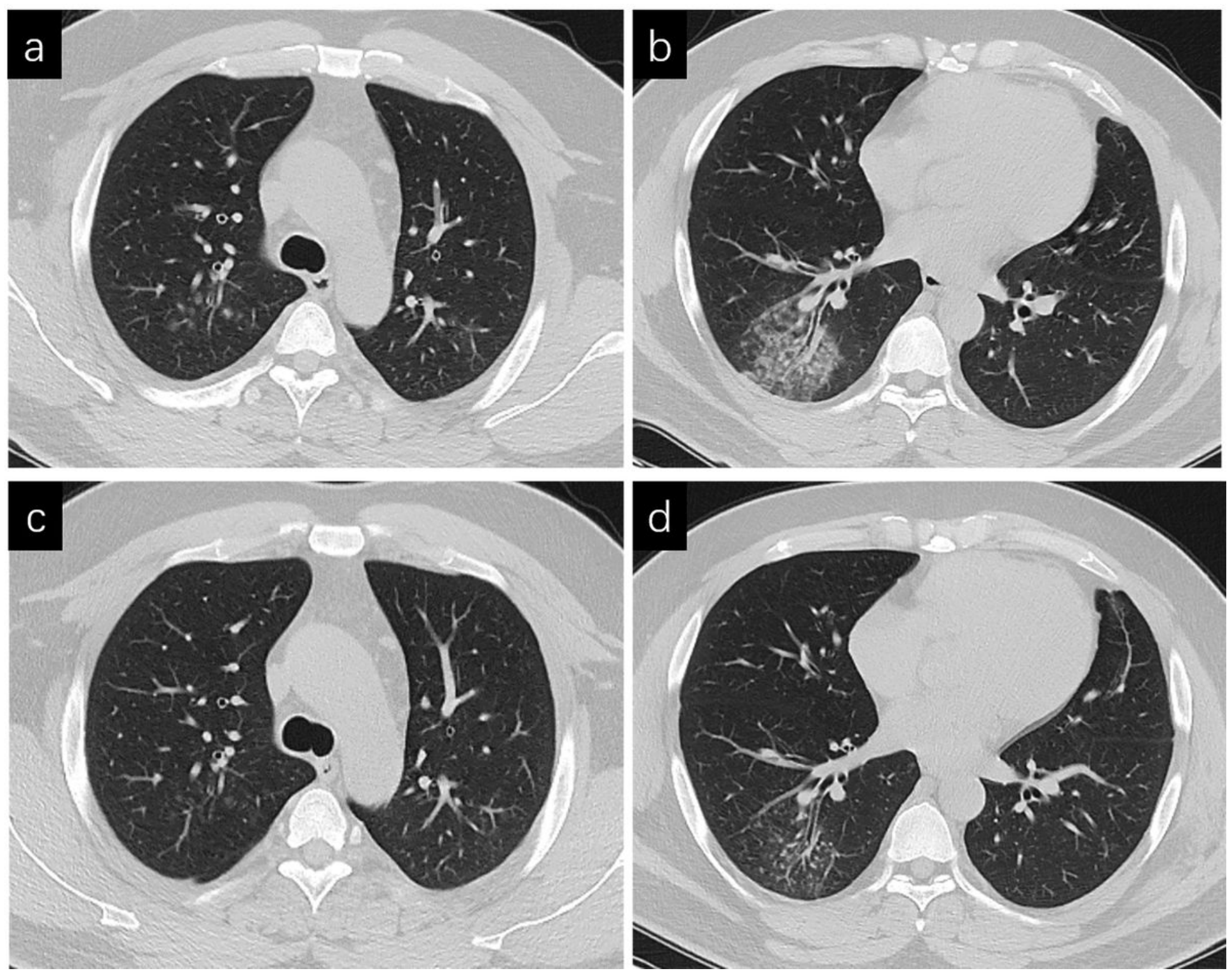

Figure 10

A 25 -year-old man presented with fever of $37.8^{\circ} \mathrm{C}$, cough, expectoration and elevated C-reactive protein $(14.06 \mathrm{mg} / \mathrm{L})$. a-b: The initial axial unenhanced CT two days after fever shows bilateral involvement of multiple ill-defined ground-glass opacities and centrilobular consolidative nodule surrounded by groundglass opacity (a), discrete nodules, tree-in-bud opacity, air bronchogram and bronchial wall thickening (b). c-d: The follow-up CT scans 7 days later shows obvious improvement of previous lesions leaving tree-inbud opacity in the right lower lobe (d). 

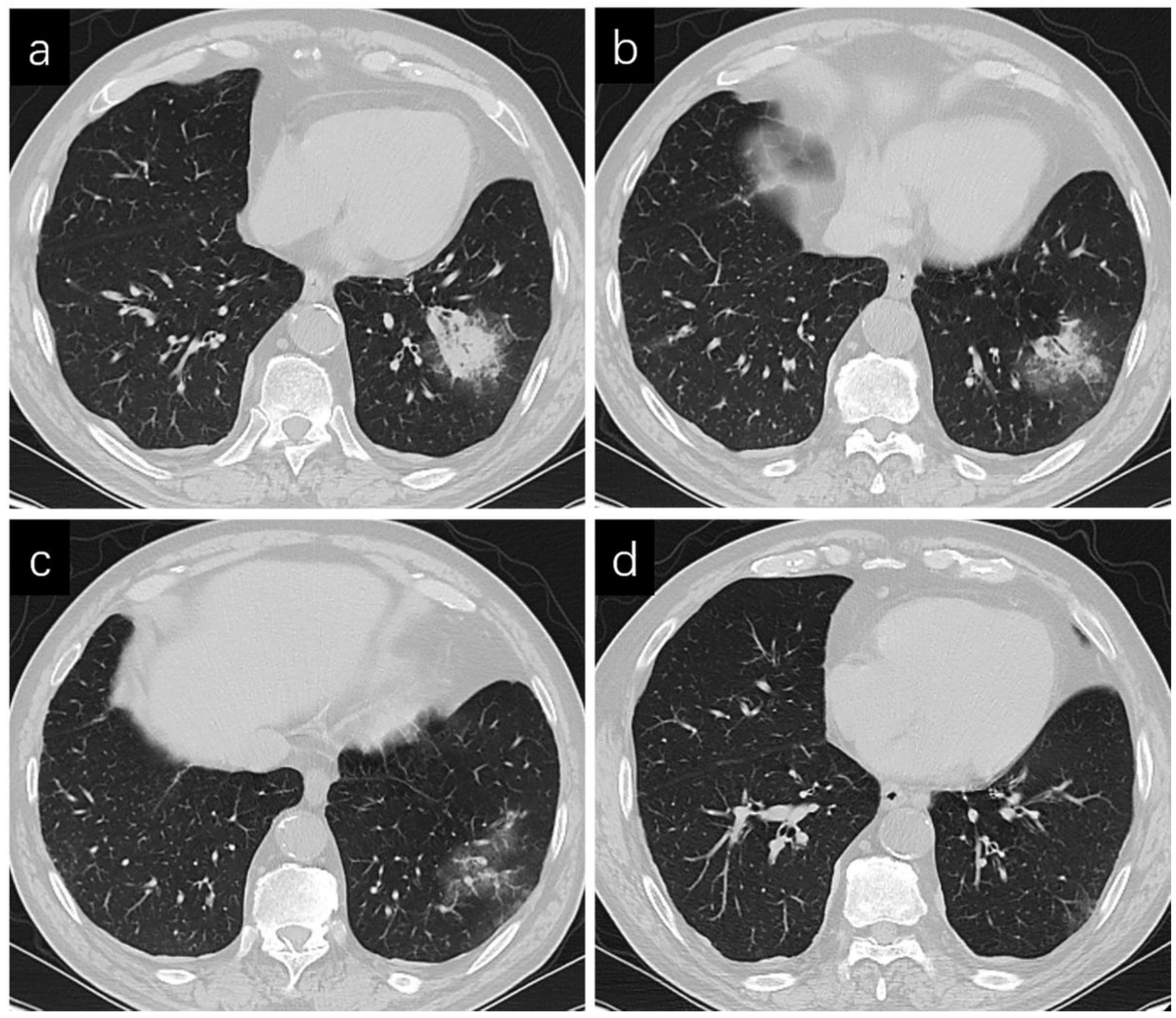

Figure 11

A 73-year-old man presented with fever of $39.2^{\circ} \mathrm{C}$, cough, expectoration and dyspnea. Laboratory test proves elevated C-reactive protein $(16 \mathrm{mg} / \mathrm{L})$, leukocytosis $\left(15.91 * 10^{\wedge} 9 / \mathrm{L}\right)$ and lymphopenia $(0.7$ ${ }^{*} 10^{\wedge} 9 / \mathrm{L}$ ). a-c: The initial axial unenhanced CT at the onset of illness shows patchy consolidation with complete halo and air bronchogram $(a, b)$, tree-in-bud opacity (b) and multiple ill-defined ground-glass opacities (c) involved left lung lower lobe. The follow-up CT scans 7 days later shows nearly complete absorption of previous lesions (d). 